\title{
High intercorneal symmetry in corneal biomechanical metrics
}

\author{
XiaoBo Zheng ${ }^{1,2}$, FangJun Bao ${ }^{1,2^{*}}$, Brendan Geraghty ${ }^{3}$, JinHai Huang ${ }^{1,2}$, AYong Yu ${ }^{1,2}$ and QinMei Wang ${ }^{1,2^{*}}$
}

\begin{abstract}
Backgroud: To evaluate the symmetry of corneal biomechanical metrics, measured using an ocular response analyzer (ORA) and self-built corneal inflation test platform, in bilateral rabbit corneas and to investigate their relationship with physical intraocular pressure (IOPp).

Methods: Twenty fresh enucleated eyes from ten rabbits were used for ex vivo whole ocular globe inflation. IOP was increased from 7.5 to $37.5 \mathrm{mmHg}$ with $7.5 \mathrm{mmHg}$ steps and biomechanical metrics were acquired using the ORA. At least 3 examinations were performed at each pressure stage. Two biomechanical metrics, corneal hysteresis $(\mathrm{CH})$ and corneal resistance factor (CRF) were recorded and analyzed as a function of IOPp. Corneal specimens were then excised from the intact ocular globe and tested under inflation conditions up to $45.7 \mathrm{mmHg}$ posterior pressure. The experimental pressure-deformation data was analyzed using an inverse modeling procedure to derive the stress-strain behavior of the cornea.

Results: A comparison of corneal shape parameters showed no statistically significant difference $(P>0.05)$ between bilateral eyes. Similarly, there were no statistically significant differences in values of $\mathrm{CH}, \mathrm{CRF}$ and corneal stiffness (as measured by the tangent modulus, Et) between bilateral eyes ( $\mathrm{CH}: F=0.94, P=0.54 ; \mathrm{CRF}: F=4.42$, $P=0.35$; Et: $F=3.15, P=0.12$ ) at different pressure levels. IOPp was highly correlated with CRF while the relationship with $\mathrm{CH}$ was less pronounced.
\end{abstract}

Conclusions: An obvious interocular symmetry in biomechanical metrics is found in this research. IOP has been shown to have important influences on the value of CRF provided by ORA.

Keywords: Intercorneal symmetry, Corneal biomechanical metrics, Corneal stiffness, Ocular response analyzer

\section{Background}

The cornea accounts for about two thirds of the refractive power of the eye and is an important component of the mechanically tough outer ocular membrane [1]. Because of its importance, a great deal of research has been conducted to understand its performance and how it responds to external and internal effects $[2,3]$. Careful evaluation of the health and adequacy of the cornea is critical for increasing the accuracy of corneal refractive surgery and ensuring the prevention of iatrogenic keratectasia [4]. The corneal mechanical properties, which

\footnotetext{
*Correspondence: bfjmd@126.com; wangqm55@126.com

${ }^{1}$ The Affiliated Eye Hospital of Wenzhou Medical University, Wenzhou, Zhejiang Province 325027, China

Full list of author information is available at the end of the article
}

are essential for maintaining its dimensional stability and hence clear vision, rely on the cornea's topography, thickness and the intrinsic properties of the tissue [5].

Refractive surgery has become a common clinical practice that is used to alter the corneal curvature to correct refractive error by controlled cutting of the corneal tissue. Several studies have shown that the biomechanical properties of the cornea play an important role in the final refractive outcome and the predictability of surgical procedures [6,7]. Biomechanical properties, which have a direct bearing on the corneal structural resistance, can affect the accuracy of intraocular pressure (IOP) measurements [8-10]. Subsequent altered corneal stiffness after ablative corneal refractive surgery can result in erroneous postoperative IOP readings measured by applanation tonometry [5]. Assessment of biomechanics is therefore important for the adequate 
understanding of corneal behavior in response to mechanical actions, refractive surgery-induced tissue remodeling or non-ablative refractive correction such as conductive keratoplasty (CK), as well as aspects of corneal physiology where mechanics plays a role (e.g. disease, injury, would healing and implants).

It is well established that a degree of symmetry has been observed in fellow eyes of most individuals. The astigmatic axis, IOP, higher-order aberrations, corneal curvature, central corneal thickness and the epithelial thickness, have similar patterns [11-15]. Marked anisometropia is uncommon, either in the magnitude of spherical or astigmatic refractive errors. Corneal biomechanics received much attention in the last few decades, and significant advances have been made in defining corneal hyperelasticity $[16,17]$, the effects of aging $[18,19]$, diabetes mellitus [20], hydration [21, 22], estrogen [23] and others. However, little progress has been made with regard to whether or not biomechanical parameters are symmetric in fellow corneas. Therefore, we sought to study the nature of the relationship between the biomechanical material properties in fellow corneas. The confirmation of high interocular symmetry may be helpful in the early assessment of ocular abnormalities, be valuable as a validation of accurate binocular data, and can also assist in the prediction of postoperative outcomes in fellow eyes. However, large asymmetry may warrant repeated clinical measurement of the eyes. Corneal biomechanical measurements are influenced by several factors, such as IOP, corneal swelling and imbibition pressures within the cornea. It is well known that IOP has an important influence on biomechanical metrics of cornea. Consequently, the current study aims to evaluate the interocular symmetry of corneal biomechanical metrics at different pressure levels.

\section{Methods}

\section{ORA measurement}

Ten Japanese white rabbits $(2-3 \mathrm{~kg})$ from the Animal Breeding Unit at Wenzhou Medical University were used in this study. All animals were treated in agreement with the ARVO Statement for Use of Animals in Ophthalmic and Vision Research and with the approval of the Animal Care and Ethics Committee of the Eye Hospital, Wenzhou Medical University. The rabbits had their IOP measured using a Tono-pen tonometer (Reichert, Inc., New York, USA) to ensure the eyes were not subjected to elevated IOP. They were euthanized by intravenous injection pentobarbital sodium overdose (Merck, Darmstadt, Germany) according to the weight $(100 \mathrm{mg} / \mathrm{kg})$ and the bilateral eyes were immediately enucleated. Both ocular response analyzer (ORA) measurements and the following corneal inflation test were performed at room temperature and within $4 \mathrm{~h}$ postmortem to reduce possible effects of post mortem tissue degradation.

An infusion needle was inserted into the vitreous body of the eye through the optic nerve to control the IOP. A transfusion bottle filled with Phosphate Buffered Saline (PBS, Maixin, China) was raised and lowered to change the pressure inside the eye, which was named as physical IOP (IOPp). The pressure was continuously monitored using a pressure transducer (DMP-HS, Hangzhou, China) as described in previous study [24]. The ORA (Reichert, Inc., New York, USA) was used to measure the corneal biomechanical metrics, corneal hysteresis $(\mathrm{CH})$ and corneal resistance factor (CRF), at five different pressure levels $(7.5,15,22.5,30$ and $37.5 \mathrm{mmHg})$. Three ORA measurements were taken at each pressure level, and the average value was used for statistical analysis. The interval between three measurements at each manometric level was at least two minutes.

\section{Corneal inflation testing procedures}

After carrying out measurements using the ORA, the corneas were extracted from the eye globes with a 3-mm ring of scleral tissue and all other ocular components were removed. As described previously [25-27], the corneas were mounted onto a custom designed pressure chamber of an inflation test rig using a mechanical clamp and cyano-acrylate glue to provide watertight connection along their ring of scleral tissue. Care was taken to avoid damage to the epithelium and endothelium. The pressure chamber was filled with PBS and connected to a reservoir, whose vertical movement was controlled by a motor to allow smooth increases and decreases in pressure.

The motor attached to the reservoir was controlled by Motion Assistant software (National Instruments Corporation, Texas, US) to set the pressure change rate at $0.427 \mathrm{mmHg} / \mathrm{s}$. All specimens were first subjected to an initial inflation pressure of $3.00 \mathrm{mmHg}$ to ensure a fully inflated and wrinkle-free corneal surface. Loading of up to $45.7 \mathrm{mmHg}$ was applied to the tissue and displacement at the corneal apex was continually monitored using a CCD laser displacement sensor (LK series, Keyence, Milton Keynes, UK) during the tests. The laser beam and pressure transducer were all connected to a personal computer to record the data automatically. The central and peripheral (approximately $1.5 \mathrm{~mm}$ away from the limbus) thicknesses of separated cornea were measured using a SP-3000 ultrasonic pachymeter (Tomey Inc, Nagoya, Japan) before the inflation test. Corneal diameters in four directions (horizontal, vertical, and two diagonal directions) were measured using a Vernier caliper. Two further initial corneal shape parameters, corneal radius $(\mathrm{R})$ and shape factor $(\mathrm{p})$ in the temporalnasal directions, were calculated from the corneal anterior profile data measured by the camera based on the 
equation: $\mathbf{y}^{2}=-\mathbf{p} \mathbf{x}^{2}+2 \mathbf{r x}$. The average value for each specimen was used in the mathematical analysis presented below. Each specimen was tested within $3 \mathrm{~h}$ postmortem.

\section{Inverse modeling}

Inverse modelling is a method that can successfully provide material behavior properties from experimental data. It is particularly useful when a simple analytical process is unavailable such as where complex geometric forms exist. Here, this method has been used to derive the gross material properties of the cornea. The design optimization software package LS-OPT (Livermore Software Technology Corp, CA, USA) was used to implement the iterative process. Finite element (FE) solver Abaqus (Dassault Systèmes Simulia Corp., Rhode Island, USA) was used to simulate the response of the cornea model based on the fixed geometric parameters and the adaptable material coefficients. The optimization software adjusted the material coefficients in order to minimize the root mean square (RMS) error between the experimental data and the response of the model; RMS $=\sqrt{\frac{1}{N} \sum_{i=1}^{N}\left(\delta_{i}^{\text {experimental }}-\delta_{i}^{\text {numerical }}\right)^{2}}$, where $N$ is the number of pressure levels $=25$, and $\delta$ the apical rise at a particular pressure, $i$.

Twenty FE models were developed representing the bilateral corneas. The models contained unique geometry, which adopted the thickness measurements taken at the cornea center and at four peripheral points, the curvature and shape factor measurements made in the nasal-temporal direction in addition to the limbal diameter measurements. Each model was constructed from 4071, 15-noded continuum elements arranged in twelve rings and one element layer representing the stroma. They also assumed encastre connection along the limbus to simulate connection to the mechanical clamps.

The global response of the models and cornea were assessed at the singularity of the pressure-apical rise measurement and no measurements of anisotropic or viscoelastic behavior was conducted. The material behavior of the cornea was therefore represented by a first order hyperelastic Ogden model with the strain energy density function:

$$
\mathrm{W}=\frac{2 \mu}{a^{2}}\left(\lambda_{1}^{\alpha}+\underline{\lambda}_{2}^{\alpha}+\underline{\lambda}_{3}^{\alpha}-3\right)+\frac{1}{D}(J-1)^{2}
$$

where $\mathrm{W}$ is the strain energy per unit volume, $\overline{\lambda_{k}}$ the deviatoric principal stretches $=\mathrm{J}^{-1 / 3} \times \lambda_{k}(\mathrm{k}=1,2,3), \lambda_{1}$, $\lambda_{2}, \lambda_{3}$ the principal stretches, $J=\lambda_{1} \lambda_{2} \lambda_{3} . \alpha$ and $\mu$ are the material parameters denoting the strain hardening exponent and the shear modulus, respectively. $D$ is a compressibility parameter, whose value is dependent on
Poisson's ratio, v; $\mathrm{D}=\frac{3(1-2 v)}{\mu(1+v)}$. Previous studies have estimated values for Poisson's ratio for ocular components, including the cornea, which ranges between 0.45 and 0.5, denoting a near incompressible behavior [28-29]. Here, corneal tissue was assumed to be incompressible. The other material coefficients, $\mu$ and $\alpha$, were obtained from the inverse modeling procedure described above. Their values were allowed to vary between 0.0001 and 1.0 , and between 20 and 350, respectively with baseline values 0.04 and 120 , which were suitable for all specimens. The use of a first order material model was found sufficient in earlier studies [30]. This reduced computation time during the inverse modeling procedure by reducing the number of variables requiring optimization.

\section{Statistical analysis}

All analyses were performed using the PASW Statistics 20.0 software (SPSS Inc., Chicago, USA). Comparison of corneal shape parameters and biomechanical metrics was performed using paired $T$ test and Hotelling $T$ Square Test, respectively. In this study, P-values of less than 0.05 were considered to be statistically significant. A second-order polynomial regression was used to explore the nonlinear correlation between IOPp and biomechanical metrics and their interocular differences.

\section{Results \\ ORA parameters}

There were no statistically significant differences between fellow eyes in corneal radius, shape factor, corneal diameter or central and peripheral corneal thickness (Table 1). The differences of $\mathrm{CH}$ and CRF among the five pressure levels between fellow eyes (Table 2) were not statistically significant $(\mathrm{CH}: \quad F=0.94, \quad P=0.54$; CRF: $F=4.42, P=0.35)$. The correlation analysis of IOPp with the two biomechanical metrics $\mathrm{CH}$ and CRF was based on a second-order polynomial regression. IOPp was weakly correlated with $\mathrm{CH}\left(\mathrm{R}^{2}=0.09,0.03\right)$ while the relationship with CRF was more pronounced $\left(R^{2}=0.84,0.83\right.$, for right and left eyes, respectively). The

Table 1 Average and standard deviation values of corneal shape parameters between right and left eyes

\begin{tabular}{lrrrl}
\hline Ocular parameters & \multicolumn{1}{c}{ Right eyes } & \multicolumn{1}{l}{ Left eyes } & \multicolumn{1}{l}{$\mathrm{t}$} & $\mathrm{P}$ \\
\hline $\mathrm{R}(\mathrm{mm})$ & $5.9 \pm 0.89$ & $5.97 \pm 0.92$ & -0.23 & 0.83 \\
$\mathrm{P}$ & $0.59 \pm 0.36$ & $0.6 \pm 0.37$ & -0.13 & 0.90 \\
$\mathrm{CCT}(\mu \mathrm{m})$ & $360.7 \pm 12.1$ & $358.7 \pm 15.7$ & 0.32 & 0.76 \\
$\mathrm{PCT}(\mu \mathrm{m})$ & $356.3 \pm 13.4$ & $351.4 \pm 15.2$ & 1.06 & 0.32 \\
$\mathrm{CD}(\mathrm{mm})$ & $12.87 \pm 0.47$ & $12.98 \pm 0.47$ & -1.87 & 0.10 \\
\hline
\end{tabular}

$R=$ corneal radius, $p=$ corneal shape factor, $C C T=$ central corneal thickness, $P C T=$ peripheral corneal thickness, $C D=$ corneal diameter 
Table 2 Average and standard deviation values of $\mathrm{CH}$ and CRF between right and left eyes at different pressure levels

\begin{tabular}{lllll}
\hline $\begin{array}{l}\text { Biomechanical } \\
\text { parameters }\end{array}$ & Pressure & Right eye & Left eye & $\begin{array}{l}\text { Interocular } \\
\text { differences }\end{array}$ \\
\hline $\mathrm{CH}$ & $7.5 \mathrm{mmHg}$ & $4.07 \pm 1.07$ & $3.83 \pm 0.63$ & $0.24 \pm 1.39$ \\
& $15.0 \mathrm{mmHg}$ & $5.02 \pm 1.12$ & $5.05 \pm 0.97$ & $-0.04 \pm 1.72$ \\
& $22.5 \mathrm{mmHg}$ & $5.41 \pm 1.92$ & $4.87 \pm 1.46$ & $0.54 \pm 2.4$ \\
& $30.0 \mathrm{mmHg}$ & $5.68 \pm 1.45$ & $4.95 \pm 2.16$ & $0.73 \pm 2.41$ \\
& $37.5 \mathrm{mmHg}$ & $5.86 \pm 2.77$ & $4.56 \pm 1.80$ & $1.02 \pm 3.25$ \\
$\mathrm{CRF}$ & $7.5 \mathrm{mmHg}$ & $0.79 \pm 0.74$ & $0.71 \pm 0.56$ & $0.31 \pm 0.79$ \\
& $15.0 \mathrm{mmHg}$ & $3.38 \pm 1.02$ & $3.12 \pm 0.74$ & $0.32 \pm 1.42$ \\
& $22.5 \mathrm{mmHg}$ & $5.30 \pm 1.54$ & $5.01 \pm 1.09$ & $0.28 \pm 1.59$ \\
& $30.0 \mathrm{mmHg}$ & $7.81 \pm 1.30$ & $7.11 \pm 1.80$ & $0.7 \pm 1.68$ \\
& $37.5 \mathrm{mmHg}$ & $10.01 \pm 2.01$ & $8.64 \pm 1.70$ & $1.11 \pm 2.39$ \\
\hline
\end{tabular}

$\mathrm{CH}=$ corneal hysteresis, $\mathrm{CRF}=$ corneal resistance factor

correlations of interocular differences of $\mathrm{CH}$ and $\mathrm{CRF}$ with IOPp were extremely low $\left(R^{2}=-0.02, R^{2}=-0.01\right)$.

\section{Experimental behavior and material constitutive models}

The pressure-apical rise behaviors of all specimens, as obtained in the fourth loading cycle, are compared in Fig. 1. In all cases, specimens exhibited an initial low stiffness and a final, considerably higher stiffness (as measured by the tangent to the pressure-displacement curve). Analysis of the interocular pressure-displacement relationships reveals a slightly different trend in behavior between fellow eyes. The inverse modeling process described above was used to obtain values for parameters $\alpha$ and $\mu$, and therefore derive a constitutive model for each cornea that provides the best possible fit (lowest RMS) with the experimentally obtained pressuredisplacement results (Table 3). Figure 2 further presented the stress-strain behavior as obtained from the inverse modeling exercise, along with a comparison between two eyes showing a slight difference of bilateral sides. The stress-strain constitutive models also enabled the determination of the tangent modulus (a measure of material stiffness) at different stress levels: $\mathrm{Et}=\mathrm{d} \sigma / \mathrm{d} \varepsilon \approx \Delta \sigma / \Delta \varepsilon$. In spite of the nonlinear form of the stress-strain results, the relationship between the tangent modulus $(\mathrm{Et})$ and the stress $(\sigma)$ was expected to be close to linear $[31,32]$. In this study, the Et- $\sigma$ relationship was assessed for all specimens. In order to quantify this effect, five stress levels $(0.001,0.002,0.003$, 0.004 and $0.005 \mathrm{MPa}$ ) were selected for analysis and comparison. The five stresses were equivalent to pressures of approximately $7.5,15,22.5,30$ and $37.5 \mathrm{mmHg}$, respectively, that represent low to high levels of IOP in rabbits and humans. Differences in Et between bilateral eyes were not statistically significant $(F=3.15, P=0.12)$ and the correlations of interocular differences of Et with IOPp were low $\left(R^{2}=-0.04\right)$.

\section{Discussion}

For assessment of the health and adequacy of corneal tissue for corneal procedures, corneal biomechanical properties can be used to screen patients for conditions including mild keratoconus or form fruste keratoconus, pellucid marginal degeneration and other ectasias. These parameters may allow earlier detection of keratoconus or identify those patients at risk for developing mild and marked keratectasia post LASIK or photorefractive keratectomy (PRK). Corneal biomechanical properties, in addition to being obtained for corneal refractive surgery, may become a critical test in glaucoma evaluation. Clinically, it may be valuable to use high symmetry in routine clinical assessments as a validation of accurate binocular data so that the absence of high symmetry may warrant repeat measurement of the eyes. An additional clinical use of this reported high symmetry in biomechanical properties is in IOP calculations for a post laser-assisted in situ keratomileusis (LASIK) eye if only one eye was treated and preoperative data was unavailable.

The ORA, one of the most commonly used tonometers, has become a popular clinical device for evaluating biomechanical properties since its launch in 2005 [33]. Although $\mathrm{CH}$ and CRF can be influenced by many factors, such as corneal health state, corneal thickness, IOP and the properties of the whole eye [33-37], they are widely accepted as an important factor in understanding the biomechanical state of the cornea and clinical diagnosis of eye diseases. Both parameters have been found to display symmetry in bilateral eyes as shown in Montard and Shen's research [38, 39]. To our knowledge, this study is the first attempt to statistically analyze the symmetry of the nonlinear corneal biomechanical properties between the right and left eyes. The non-statistically significant differences of $\mathrm{CH}$ and CRF remained stable among the five pressure levels between fellow eyes and demonstrated symmetrical nonlinear corneal biomechanical properties. Similar to an earlier study by Roberts [40], the present results showed that eyes displayed variable biomechanical metrics with different values of IOP (Table 2). Although no statistically significant differences were observed in $\mathrm{CH}$ and $\mathrm{CRF}$ for bilateral rabbit eyes during the current study, a previous study by Tejwani et al. [41] reported differences in human eyes. However, ORA metrics were measured at exactly the same IOP levels for both eyes in the current study while there was a $1.2 \mathrm{mmHg}$ difference between IOPcc for left and right eyes in Tejwani's study. It is now known that IOP can have important influences on most corneal biomechanical metrics provided by the ORA, as mentioned in our previous research [24]. Therefore, it is possible that this IOP difference may have contributed to the observed differences in the ORA metrics reported by Tejwani et al. 

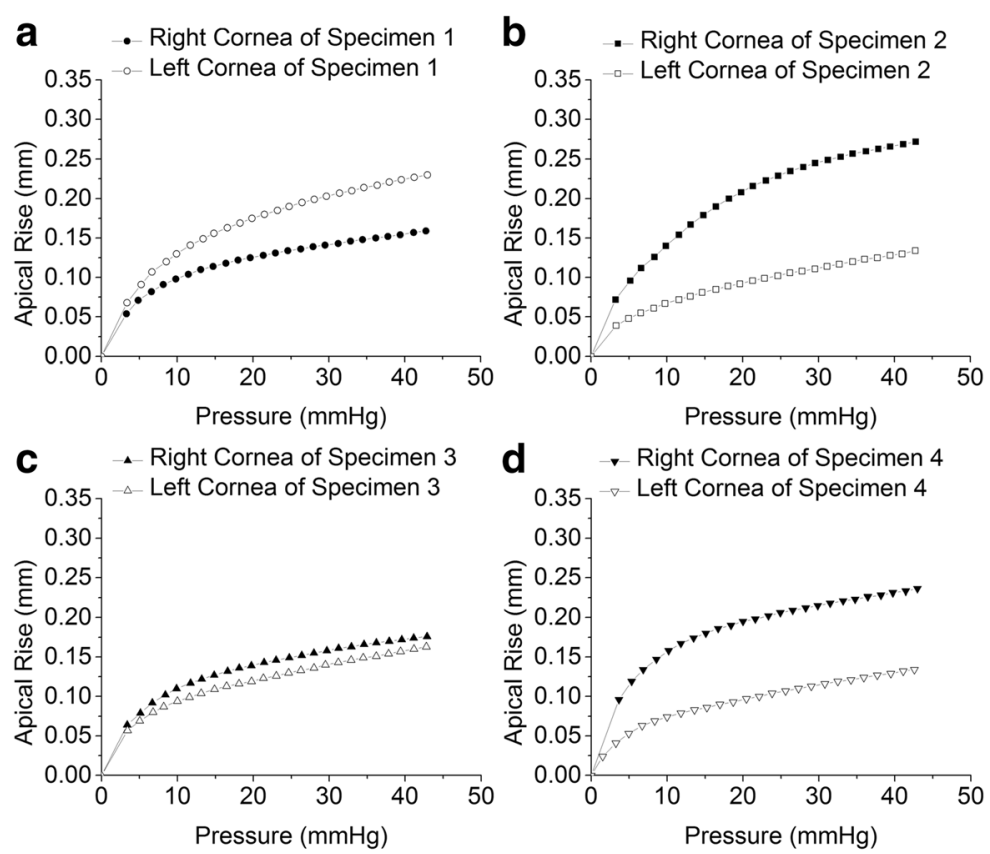

d $\quad$ Right Cornea of Specimen 4

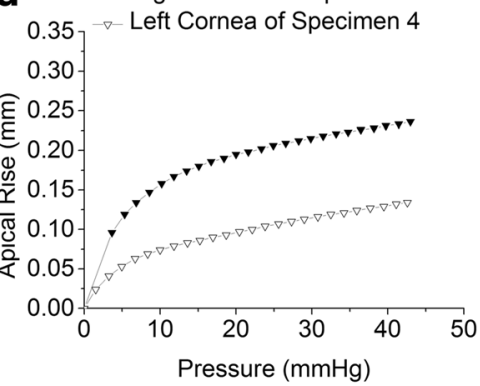

e $\quad$ - Right Cornea of Specimen 5
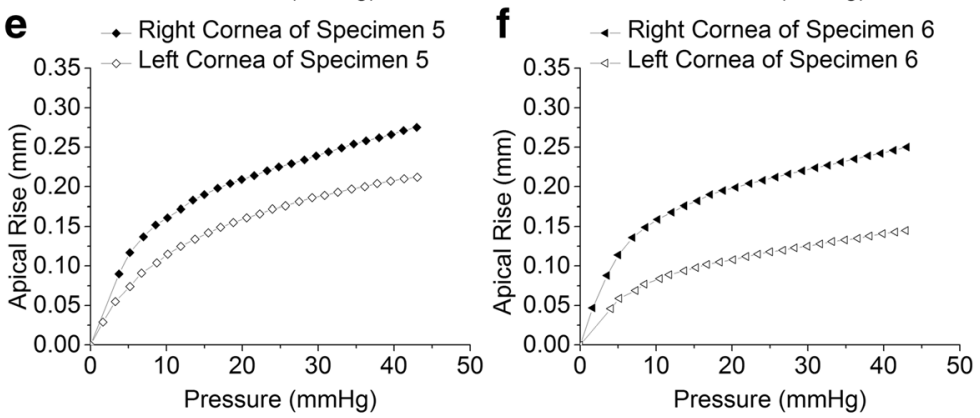

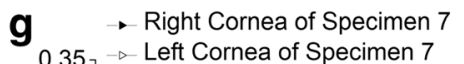

h $\quad$ - Right Cornea of Specimen 8
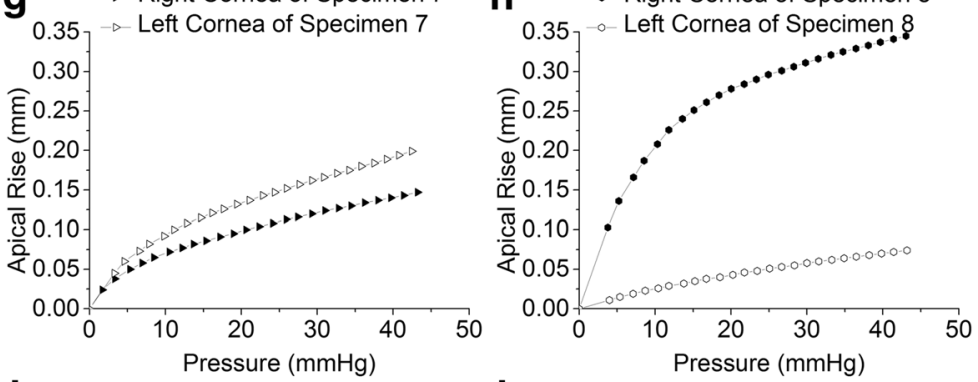

i $\quad \star$ Right Cornea of Specimen 9
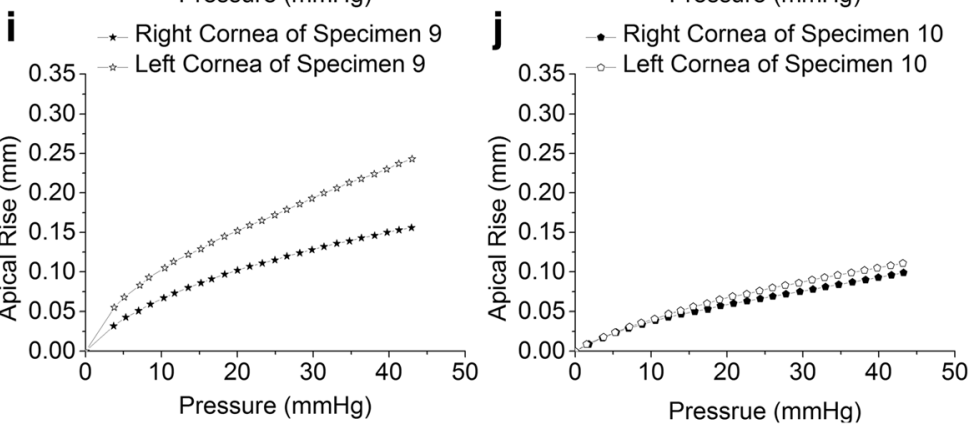

Fig. 1 Pressure-rise behavior of corneal specimens between right and left eyes, "a-j" means specimen 1 to specimen 10 
Table 3 Average and standard deviation values of tangent modulus between right and left eyes at different stress levels

\begin{tabular}{lcccc}
\hline $\begin{array}{l}\text { Biomechanical } \\
\text { parameters }\end{array}$ & Stress $(\mathrm{MPa})$ & Right eye & Left eye & $\begin{array}{l}\text { Interocular } \\
\text { differences }\end{array}$ \\
\hline Tangent Modulus & 0.001 & $0.5 \pm 0.39$ & $0.86 \pm 0.83$ & $-0.36 \pm 0.87$ \\
& 0.002 & $0.6 \pm 0.39$ & $0.97 \pm 0.82$ & $-0.37 \pm 0.89$ \\
& 0.003 & $0.71 \pm 0.4$ & $1.09 \pm 0.82$ & $-0.38 \pm 0.92$ \\
& 0.004 & $0.82 \pm 0.42$ & $1.21 \pm 0.83$ & $-0.39 \pm 0.95$ \\
& 0.005 & $0.94 \pm 0.43$ & $1.34 \pm 0.83$ & $-0.41 \pm 0.98$ \\
\hline
\end{tabular}

$\mathrm{CH}$ had a weak correlation with IOP whereas a strong positive correlation was found between CRF and IOP. However, the results presented herein were different from other studies [42-44]. This may be caused by differences in pressure measurement methods, specimen species and the type of mount used in the experimental set up. For instance, the current study directly measured IOP using a pressure transducer whereas transcorneal pressure was measured in other studies [42-44]. These studies also used anterior chamber mounts while a whole-globe mount was used in the current study. Consequently, the measurements obtained from the ORA may be affected by the scleral stiffness in addition to that of the cornea. Furthermore, the collagen orientation in rabbit and porcine corneas has been shown to differ from that of human's [45], which may result in altered mechanical response.

Although various approaches have been designed to measure corneal biomechanical properties in vivo [33, 46], efforts to determine the tangent modulus still rely on ex vivo experiments involving human and in some cases animal corneas. The use of animal corneas [25, 47] (e.g. rabbit and pig) as an approximate model for human corneas in mechanical property characterization were particularly important in light of the need to acquire statistically significant material property data, which is extremely difficult to obtain from human donor corneas. A number of studies on the mechanics of the cornea, both intact and cut into strips, have been published which confirmed its viscoelastic, nonlinear material behavior $[48,49]$. The stress strain relationship can be divided into two distinctive phases: the matrix regulated phase with low stiffness and collagen regulated phase with much higher stiffness [50]. The fundamental biomechanical parameter, tangent modulus, is defined as the tangent ratio of the stress and strain relationship and is not a constant. Also, it is shown that high and stable interocular corneal symmetry exist in the tangent modulus of normal corneas at different stress levels. Compilation of normative data on corneal tangent modulus may assist in detecting early keratoconus.

The values of $\mathrm{CH}$ and $\mathrm{CRF}$ in left eyes were lower than those observed in right eyes whereas Et was higher in the left eyes when compared to right eyes. However, the differences were not statistically significant and may be due to the small sample size or influenced by noise. Interocular biomechanical differences increased as IOP was increased, a finding that could be linked with corneal edema [51]. At an IOP of $40 \mathrm{mmHg}$ and a temperature around $15{ }^{\circ} \mathrm{C}$, the corneal imbibition pressure may reduce and draw water into the corneal stroma $[52,53]$. The resulting increase in water content can change corneal biomechanical properties without

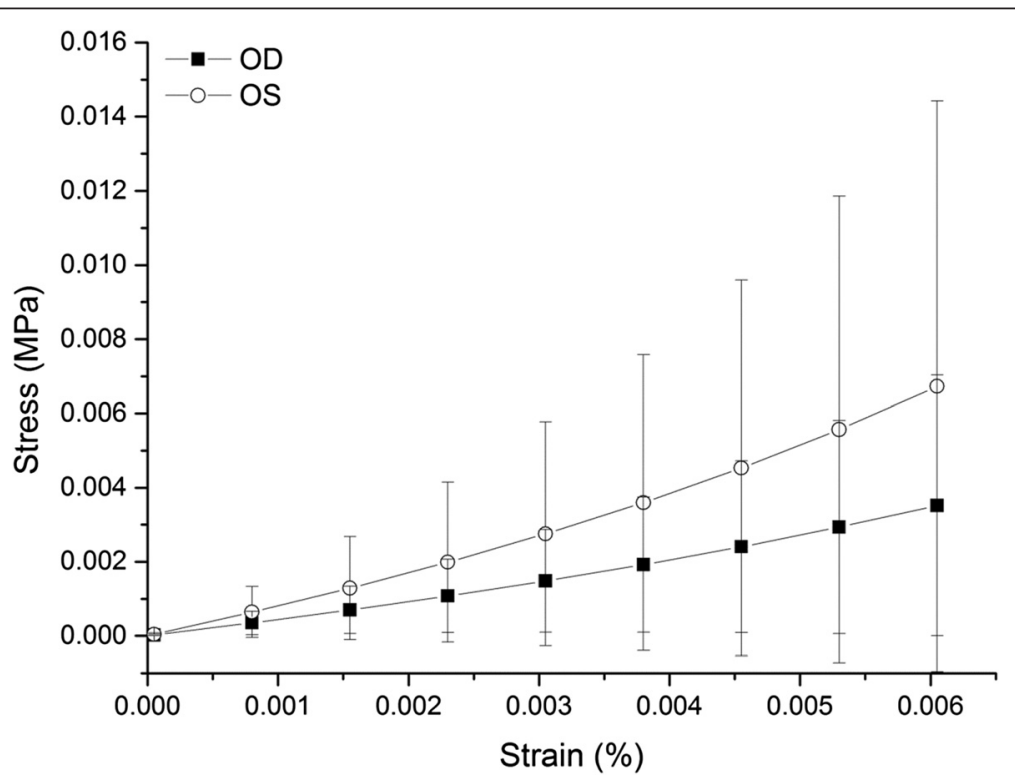

Fig. 2 Comparison of average stress-strain behavior between right and left eyes. The error bars represent the standard deviation of stress values 
apparent morphological effects [53]. Since the "border pressure" inducing this phenomenon is slightly different for each cornea, the effect caused by the increasing IOP can vary for corneas and induce increased differences between eyes at increased pressure levels.

\section{Conclusions}

In conclusion, although a large range of values exists in $\mathrm{CH}, \mathrm{CRF}$ and the corneal tangent modulus, there was a very high interocular symmetry between right and left normal corneas. Further studies may disclose how well variations in this high symmetry could be used to predict abnormalities of the cornea including post postoperative keratectasia and quality of visual outcomes after corneal refractive surgery. Moreover, the results of the current study could be useful in aiding the development of new technologies that aim to eliminate the effect of corneal biomechanical properties on transcorneal IOP measurements. These results may also provide useful information that could help evaluate the status of the corneal endothelial barrier and hence the endothelial cells that play an important role in imbibition pressure maintenance and the prevention of corneal swelling. Due to the difficulty in obtaining sufficiently large numbers of human eyes for research purposes, the current study has attempted to address these issues using rabbit eyes due to their similarity to human eyes. Nevertheless, validation of the results in human eyes will be essential before translating into clinical understanding and practice.

\section{Competing interests}

The authors declare that they have no competing interests.

\begin{abstract}
Authors' contributions
FJB and QMW provided conception and design, revised it critically for important intellectual content and supervision. XBZ, FJB, BG, JHH, AYY and QMW participated in data acquisition, drafted the article and contributed to statistical analysis. All authors read and approved the final manuscript.
\end{abstract}

\section{Financial support}

This study was supported by the Science and Technology Plan Project of Wenzhou Science and Technology Bureau (C20120009-04), Science Foundation of the Affiliated Eye Hospital of Wenzhou Medical University (YNCX201312, YNCX201405, YNZD201501) and the National Natural Science Foundation of China (81300807)

\section{Author details}

'The Affiliated Eye Hospital of Wenzhou Medical University, Wenzhou, Zhejiang Province 325027, China. ${ }^{2}$ The Institution of Ocular Biomechanics, Eye Hospital, Wenzhou Medical University, No. 270\# Xueyuan West Road, Wenzhou City, Zhejiang Province 325027, China. ${ }^{3}$ School of Engineering, University of Liverpool, Liverpool L69 3GH, UK.

Received: 26 October 2015 Accepted: 20 February 2016

Published online: 05 March 2016

\section{References}

1. Fatt I. Physiology of the eye: An Introduction to the Vegetative Functions. London: Butterworths; 1978. p. 1-42.

2. Jue B, Maurice DM. The mechanical properties of the rabbit and human cornea. J Biomech. 1986;19:847-53.
3. Kurita Y, lida Y, Kaneko M, Mishima HK, Katakura S, Kiuchi Y. Simultaneous measurement of eye stiffness and contact area for living human eyes. Conf Proc IEEE Eng Med Biol Soc. 2007;2007:2779-82.

4. Seiler T, Koufala K, Richter G. latrogenic keratectasia after laser in situ keratomileusis. J Refract Surg. 1998;14:312-7.

5. Liu J, Roberts CJ. Influence of corneal biomechanical properties on intraocular pressure measurement: quantitative analysis. J Cataract Refract Surg. 2005;31:146-55.

6. Roberts C. The cornea is not a piece of plastic. J Refract Surg. 2000;16:407-13.

7. Roberts C. Biomechanical customization: the next generation of laser refractive surgery. J Cataract Refract Surg. 2005;31:2-5.

8. Weinreb RN, Brandt JD, Garway-Heath DF, Medeiros F. Intraocular Pressure. The Hague: Kugler Publications; 2007.

9. Hamilton KE, Pye DC. Young's modulus in normal corneas and the effect on applanation tonometry. Optom Vis Sci. 2008:85:445-50.

10. Ogbuehi KC, Osuagwu UL. Corneal biomechanical properties: precision and influence on tonometry. Cont Lens Anterior Eye. 2014;37:124-31.

11. McKendrick AM, Brennan NA. The axis of astigmatism in right and left eye pairs. Optom Vis Sci. 1997;74:668-75.

12. Realini T, Vickers WR. Symmetry of fellow-eye intraocular pressure responses to topical glaucoma medications. Ophthalmology. 2005;112:599-602.

13. Harris WF. Technical note: accounting for anatomical symmetry in the first-order optical character of left and right eyes. Ophthalmic Physiol Opt. 2007;27:412-5

14. Myrowitz EH, Kouzis AC, O'Brien TP. High interocular corneal symmetry in average simulated keratometry, central corneal thickness, and posterior elevation. Optom Vis Sci. 2005:82:428-31.

15. Reinstein DZ, Archer TJ, Gobbe M, Silverman RH, Coleman DJ. Epithelial thickness in the normal cornea: three-dimensional display with Artemis very high-frequency digital ultrasound. J Refract Surg. 2008;24:571-81.

16. Bryant M, McDonnell P. Constitutive laws for biomechanical modelling of refractive surgery. J Biomech Eng. 1996;118:473-81.

17. Kampmeier J, Radt B, Birngruber R, Brinkmann R. Thermal and biomechanical parameters of porcine cornea. Cornea. 2000;19:355-62.

18. Elsheikh A, Wang D, Brown M, Rama P, Campanelli M, Pye D. Assessment of corneal biomechanical properties and their variation with age. Curr Eye Res. 2007;32:11-9.

19. Meek KM, Leonard DW, Connon CJ, Dennis S, Khan S. Transparency, swelling and scarring in the corneal stroma. Eye (Lond). 2003;17:927-36.

20. Kotecha A, Oddone F, Sinapis C, Elsheikh A, Sinapis D, Sinapis A, et al. Corneal biomechanical characteristics in patients with diabetes mellitus. J Cataract Refract Surg. 2010;36:1822-8.

21. Daxer A, Misof K, Grabner B, Ettl A, Fratzl P. Collagen fibrils in the human corneal stroma: structure and aging. Invest Ophthalmol Vis Sci. 1998;39:644-8.

22. Hamilton KE, Pye DC, Aggarwala S, Evian S, Khosla J, Perera R. Diurnal variation of central corneal thickness and Goldmann applanation tonometry estimates of intraocular pressure. J Glaucoma. 2007;16:29-35.

23. Spoerl E, Zubaty V, Raiskup-Wolf F, Pillunat LE. Oestrogen-induced changes in biomechanics in the cornea as a possible reason for keratectasia. $\mathrm{Br} J$ Ophthalmol. 2007;91:1547-50.

24. Bao F, Deng M, Wang Q, Huang J, Yang J, Whitford C, et al. Evaluation of the relationship of corneal biomechanical metrics with physical intraocular pressure and central corneal thickness in ex vivo rabbit eye globes. Exp Eye Res. 2015;137:11-7.

25. Ni S, Yu J, Bao F, Li J, Elsheikh A, Wang Q. Effect of glucose on the stressstrain behavior of ex-vivo rabbit cornea. Exp Eye Res. 2011;92:353-60.

26. Yu JG, Bao FJ, Feng YF, Whitford C, Ye T, Huang YB, et al. Assessment of corneal biomechanical behavior under posterior and anterior pressure. J Refract Surg. 2013;29:64-70.

27. Yu JG, Bao FJ, Joda A, Fu XA, Zhou S, Wang J, et al. Influence of glucocorticosteroids on the biomechanical properties of in-vivo rabbit cornea. J Mech Behav Biomed Mater. 2014;29:350-9.

28. Grupcheva CN, Malik TY, Craig JP, McGhee CN. In vivo confocal microscopy of corneal epithelial ingrowth through a laser in situ keratomileusis flap buttonhole. J Cataract Refract Surg. 2001;27:1318-22.

29. Dhaliwal DK, Romanowski EG, Yates KA, Hu D, Mah FS, Fish DN, et al. Valacyclovir inhibition of recovery of ocular herpes simplex virus type 1 after experimental reactivation by laser in situ keratomileusis. J Cataract Refract Surg. 2001;27:1288-93.

30. Mulhern MG, Condon PI, O'Keefe M. Myopic and hyperopic laser in situ keratomileusis retreatments: indications, techniques, limitations, and results. J Cataract Refract Surg. 2001;27:1278-87. 
31. Elsheikh A, Wang D, Pye D. Determination of the modulus of elasticity of the human cornea. J Refract Surg. 2007;23:808-18.

32. Elsheikh A, Alhasso D, Rama P. Biomechanical properties of human and porcine corneas. Exp Eye Res. 2008;86:783-90.

33. Luce DA. Determining in vivo biomechanical properties of the cornea with an ocular response analyzer. J Cataract Refract Surg. 2005;31:156-62.

34. Tas M, Oner V, Ozkaya E, Durmus M. Evaluation of corneal biomechanical properties in patients with rheumatoid arthritis: a study by ocular response analyzer. Ocul Immunol Inflamm. 2014;22(3):224-7.

35. Kotecha A, Elsheikh A, Roberts CR, Zhu H, Garway-Heath DF. Corneal thickness- and age-related biomechanical properties of the cornea measured with the ocular response analyzer. Invest Ophthalmol Vis Sci. 2006;47:5337-47.

36. Chang PY, Chang SW, Wang JY. Assessment of corneal biomechanical properties and intraocular pressure with the ocular response analyzer in childhood myopia. Br J Ophthalmol. 2010;94:877-81.

37. Sullivan-Mee M, Billingsley SC, Patel AD, Halverson KD, Alldredge BR, Qualls C. Ocular response analyzer in subjects with and without glaucoma. Optom Vis Sci. 2008;85:463-70.

38. Montard R, Kopito R, Touzeau O, Allouch C, Letaief I, Borderie V, et al. Ocular response analyzer: feasibility study and correlation with normal eyes. J Fr Ophtalmol. 2007;30:978-84

39. Shen M, Wang J, Qu J, Xu S, Wang X, Fang H, et al. Diurnal variation of ocular hysteresis, corneal thickness, and intraocular pressure. Optom Vis Sci. 2008:85:1185-92.

40. Roberts CJ. Concepts and misconceptions in corneal biomechanics. J Cataract Refract Surg. 2014;40:862-9.

41. Tejwani S, Shetty R, Kurien M, Dinakaran S, Ghosh A, Roy AS. Biomechanics of the cornea evaluated by spectral analysis of waveforms from ocular response analyzer and Corvis-ST. PLoS One. 2014;9:e97591.

42. Tao C, Han Z, Sun Y, Zhou C, Roberts C, Zhou D, et al. Corneal hysteresis with intraocular pressure of a wide range: a test on porcine eyes. J Refract Surg. 2013;29:850-4.

43. Alhamad TA, Meek KM. Comparison of factors that influence the measurement of corneal hysteresis in vivo and in vitro. Acta Ophthalmol. 2011;89:e443-50

44. Neuburger M, Maier P, Bohringer D, Reinhard T, Jordan J F. The impact of corneal edema on intraocular pressure measurements using goldmann applanation tonometry, Tono-Pen XL, iCare, and ORA: an in vitro model. J Glaucoma. 2013;22:584-90.

45. Hayes S, Boote C, Lewis J, Sheppard J, Abahussin M, Quantock AJ, et al. Comparative study of fibrillar collagen arrangement in the corneas of primates and other mammals. Anat Rec (Hoboken). 2007;290:1542-50.

46. Wang H, Prendiville PL, McDonnell PJ, Chang WV. An ultrasonic technique for the measurement of the elastic moduli of human cornea. J Biomech. 1996;29:1633-6.

47. Wollensak G, lomdina E. Long-term biomechanical properties of rabbit cornea after photodynamic collagen crosslinking. Acta Ophthalmol. 2009;87:48-51.

48. Nyquist G. Rheology of the cornea: experimental techniques and results. Exp Eye Res. 1968;7:183-8.

49. Woo SL, Kobayashi AS, Schlegel WA, Lawrence C. Nonlinear material properties of intact cornea and sclera. Exp Eye Res. 1972;14:29-39.

50. Anderson K, El-Sheikh A, Newson T. Application of structural analysis to the mechanical behaviour of the cornea. J R Soc Interface. 2004;1:3-15.

51. Kling S, Marcos S. Effect of hydration state and storage media on corneal biomechanical response from in vitro inflation tests. J Refract Surg. 2013;29:490-7.

52. Melamed S, Ben-Sira I, Ben-Shaul Y. Corneal endothelial changes under induced intraocular pressure elevation: a scanning and transmission electron microscopic study in rabbits. Br J Ophthalmol. 1980;64:164-9.

53. Kaye Gl, Sibley RC, Hoefle FB. Recent studies on the nature and function of the corneal endothelial barrier. Exp Eye Res. 1973;15:585-613.

\section{Submit your next manuscript to BioMed Central and we will help you at every step:}

- We accept pre-submission inquiries

- Our selector tool helps you to find the most relevant journal

- We provide round the clock customer support

- Convenient online submission

- Thorough peer review

- Inclusion in PubMed and all major indexing services

- Maximum visibility for your research

Submit your manuscript at www.biomedcentral.com/submit
Biomed Central 